\title{
A literatura e a CONSTRUÇÃo De livroS
}

\author{
Angelo Mazzuchelli Garcia \\ Doutorando em Estudos Literários, Faculdade de Letras/UFMG
}

\begin{abstract}
RESUMO
O presente artigo trata das poéticas visuais da literatura atreladas ao conceito de livro como um objeto artístico e manuseável. A abordagem enfoca algumas das primeiras obras modernistas européias que podem ser incluídas na categoria livro-objeto ou livro de artista. Num segundo estágio, atinge-se o Concretismo brasileiro, do qual emigra o poeta Wlademir Dias Pino para fundar o movimento Poema-processo, cuja teoria nasce vinculada a dois livros: A ave - considerado o primeiro livro de artista brasileiro - e Solida, ambos de Pino.
\end{abstract}

\section{PALAVRAS - CHAVE}

Livro-objeto, livro de artista, livro-poema

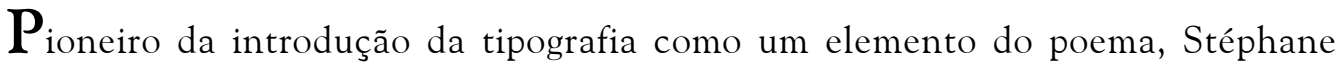
Mallarmé irrompeu, com Un coup de dés, novos caminhos, tanto para a literatura, quanto para as artes plásticas. Caminhos abertos por uma espécie de reação em cadeia: começando pela sonoridade, pela importância atribuída a cada palavra na declamação do poema; isso determinou a necessidade de uma hierarquização, obtida através do uso da diferenciação tipográfica; a tipografia conduziu à superfície da página, ao planejamento da mesma; e, finalmente, o planejamento das páginas conduziu à totalidade do livro. Explorando a realidade (tipo)gráfica da palavra, Mallarmé atinge outras realidades, intrínsecas à (tipo)gráfica: a realidade da página e a do livro como objeto, sobretudo como objeto manuseável.

Desde a origem da tipografia, houve conflito entre a forma e o conteúdo. A forma era o livro impresso. O conteúdo era o pensamento. [...] A partir do século XIX, a dinâmica da arte tipográfica incentivou uma irresistível união entre o significante e o significado. ${ }^{1}$

Os ideais de Mallarmé situam-se na origem de novas concepções de livro que, por vezes, deixa de ser apenas suporte e passa a atuar como significante. Un coup de dés ${ }^{2}$ já vislumbra uma inovação nesse sentido: a leitura do poema converte duas páginas abertas do livro em espaço único. Essa nova fórmula de leitura (que, até então, só era concebida página por página) reverbera no livro como um todo: segundo Maurice Blanchot, há uma busca de "enriquecer a leitura analítica pela visão global e simultânea,

\footnotetext{
${ }^{1}$ JEAN. A escrita, p. 136.

${ }^{2}$ O poema foi publicado, em Paris, primeiramente, dentro da revista Cosmopolis, em 1897, e, depois, em 1914, em formato livro.
} 
enriquecer também a visão estática pelo dinamismo do jogo de movimentos". ${ }^{3} \mathrm{O}$ texto de Mallarmé convida não só à leitura simultânea de duas páginas, mas também a uma leitura global: se, por um lado, um conjunto de duas páginas possui diferentes tipos e tamanhos de caracteres, por outro, caracteres do mesmo tipo e do mesmo tamanho (ou seja, equivalentes em sonoridade) que aparecem ao longo do livro convertem-se, individualmente, em elos que interconectam graficamente diferentes páginas.

Foi exatamente a idéia de simultaneidade o fator determinante para a criação do livro La Prose du Transsibérien et de la Petite Jehanne de France (Fig. 1 e 1A; cf. Pranchas 14a e 14b, p. 384), de Sonia Delaunay-Terk e Blaise Cendrars (Frédéric Sauser), publicado em 1913, em Paris. Os autores qualificaram a criação conjunta como o primeiro livro simultâneo. Entretanto, a simultaneidade, nesse caso, difere da simultaneidade evocada por Blanchot, ligada ao dinamismo do ato de manusear um livro. A simultaneidade de La Prose du Transsibérien evoca uma integração entre as artes da palavra e as da imagem. $\mathrm{O}$ livro tem cerca de dois metros de altura ${ }^{4}$ e é composto por um conjunto de manchas coloridas (uma espécie de cascata, pintada por Sonia Delaunay-Terk), justapostas a um texto (de Blaise Cendrars). ${ }^{5}$ Mas foi uma experiência isolada. As mais intensas e produtivas explorações

Fig. 1: Sonia Delaunay-Terk (1885-1979) e Blaise Cendrars (Frédéric Sauser, $1887-$ 1961), La Prose du Transsibérien et de la Petite Jehanne de France, 1913.200 × 35,7 cm.

Tiragem: 150 exemplares. Fonte da imagem: PEYRÉ, Yves. Peinture et poésie.
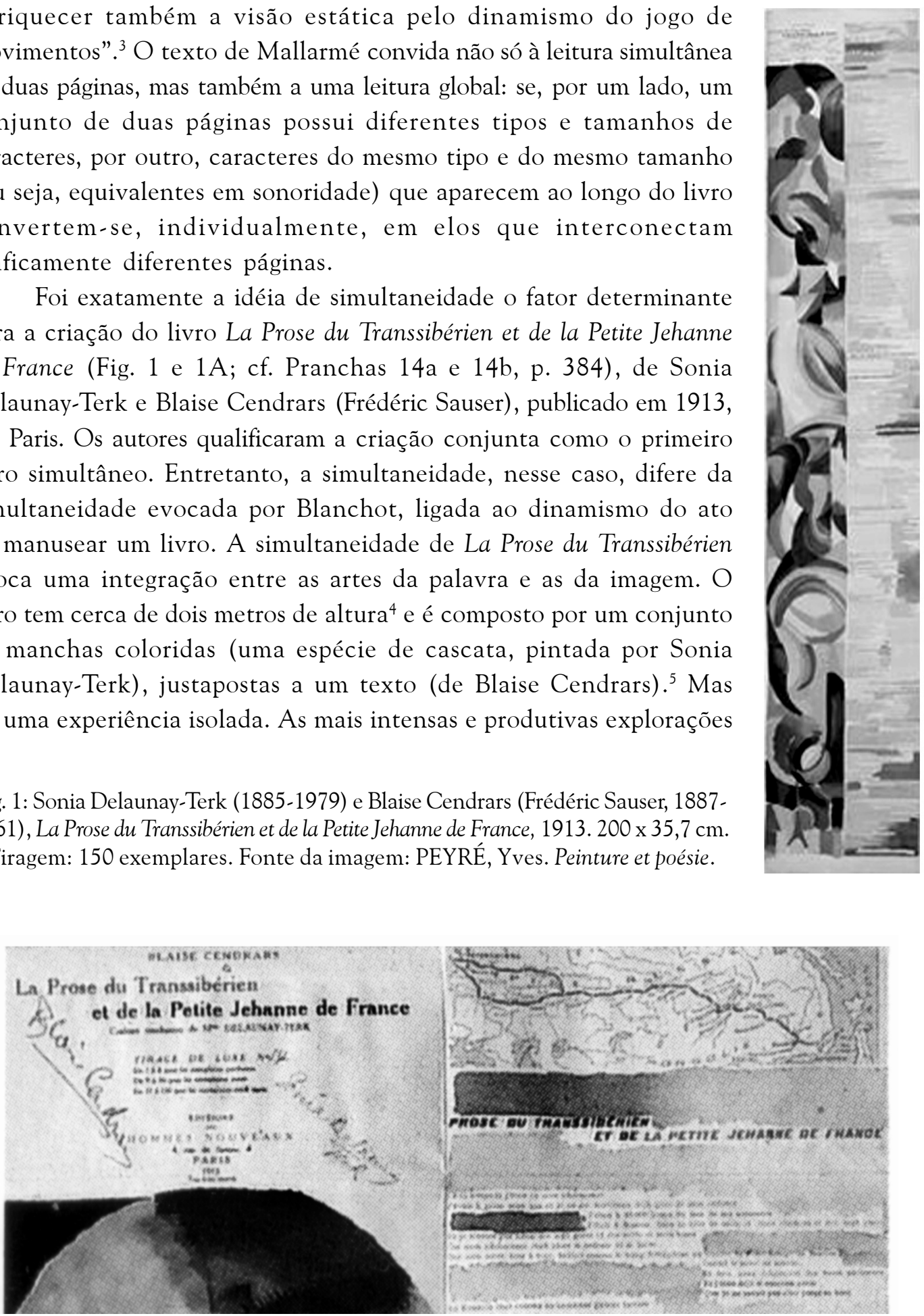

Fig. 1A: Detalhe.

\footnotetext{
${ }^{3}$ Citado por SILVEIRA. A página violada, p. 159.

${ }^{4} \mathrm{O}$ livro é um folheto desdobrável, composto por 4 folhas reunidas (respectivamente: 54,7 x 35,7; 51,5 x 35,7; 49,7 × 35,7; 51,5 × 35,7 cm), dobrado em dois pela largura e, variando de acordo com o exemplar, em 18,20 ou 22 pela altura. Aberto, o livro mede $200 \times 35,7 \mathrm{~cm}$.
}

${ }^{5} \mathrm{O}$ texto reconta a viagem de Cendrars, de trem, de Moscou ao Mar do Japão, em 1904. 
aliadas à estética do livro, durante as primeiras décadas do século $\mathrm{XX},{ }^{6}$ couberam ao Futurismo na Itália e ao Cubo-futurismo na Rússia.

O movimento italiano - que glorificava as inovações tecnológicas do mundo moderno - foi lançado em 1909, por Filippo Tommaso Marinetti. O Futurismo propunha eliminar a sintaxe, concedendo, assim, liberdade às palavras. Ao propor as parole in libertà, Marinetti pretendia provocar uma explosão tipográfica na página futurista. $O$ poeta italiano considerava repugnante a tradicional idéia de harmonia tipográfica da página; segundo ele, deveriam ser usados tantos tamanhos e formas de tipos e tantas cores quantos fossem necessários. Desse modo, a força expressiva das palavras seria duplicada. A página deveria ser a expressão do pensamento e do dinamismo futurista.

Mas a revolução proposta por Marinetti não se limitava à superfície da página: o próprio objeto livro deveria expressar o pensamento futurista. Ambicionando criar um signo da Idade da Máquina, Fortunato Depero lança, em 1927, Depero futurista (Fig. 2), um livro encadernado com dois grandes parafusos e duas grandes porcas. Provavelmente o primeiro livro de $\operatorname{artista}^{7}$ a incorporar elementos plásticos inusitados numa estrutura de códice, Depero futurista foi chamado pelos futuristas de "o primeiro livro mecânico". Cinco anos após o lançamento do livro de Depero, surge o que talvez tenha sido o signo definitivo da Idade da Máquina - o primeiro livro impresso em folhas de metal: Parole in libertà: olfattive, tattili, termiche (Fig. 3), de Marinetti. Publicado pela Litolatta, editora especializada em

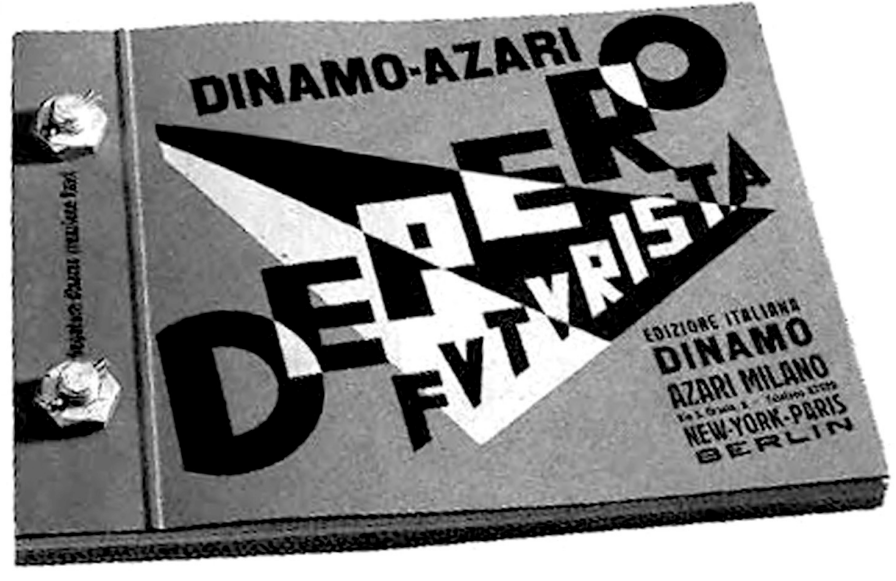

Fig. 2: Fortunato Depero (1892-1960), Depero futurista, 1927. Fonte da imagem: HOLLIS, Richard. Design gráfico: uma história concisa. São Paulo: Martins Fontes, 2001.

\footnotetext{
${ }^{6} \mathrm{Na}$ Inglaterra, no final do período vitoriano, já havia um interesse em produzir livros bem compostos, com ênfase no trabalho artesanal, por iniciativa de William Morris e do movimento Artes e ofícios. Já no século XX, outras iniciativas direcionadas à estética do livro partiram, destacadamente, da Bauhaus, escola de artes e ofícios fundada em 1919, em Weimar, Alemanha. Os livros produzidos pela Bauhaus, a maior parte projetada por Lazlo Moholy-Nagy, já se apoiavam na crescente mecanização de então.

${ }^{7}$ O livro de artista é uma categoria artística em que se explora, através de intervenções gráficas e/ou plásticas, os conceitos vinculados à idéia de livro - tridimensionalidade, manuseabilidade, leitura, paginação, encadernação etc.
} 


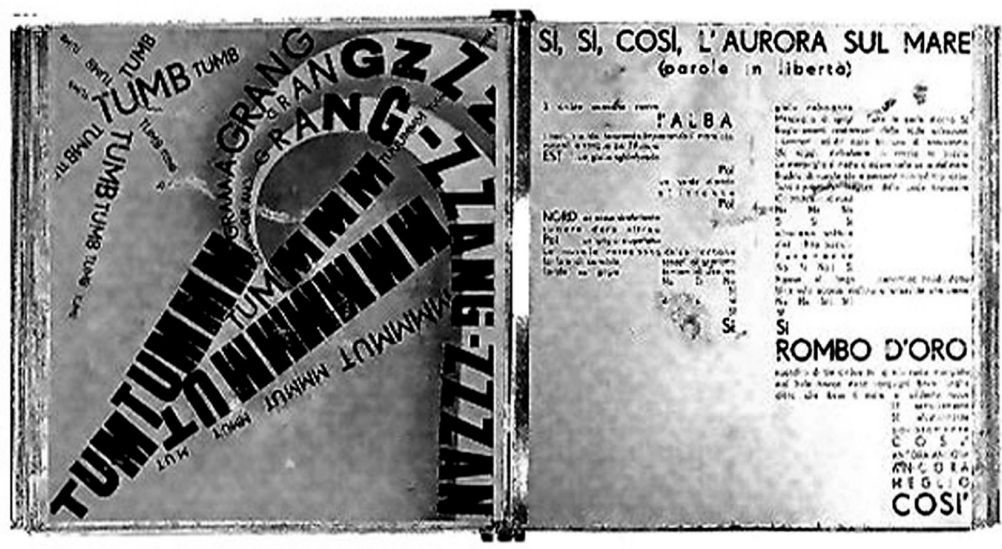

Fig. 3: Filippo Tommaso Marinetti (1876-1944), Parole in libertà: olfattive, tattili, termiche, 1932.

Fonte da imagem: http://colophon.com/gallery/futurism/index.html
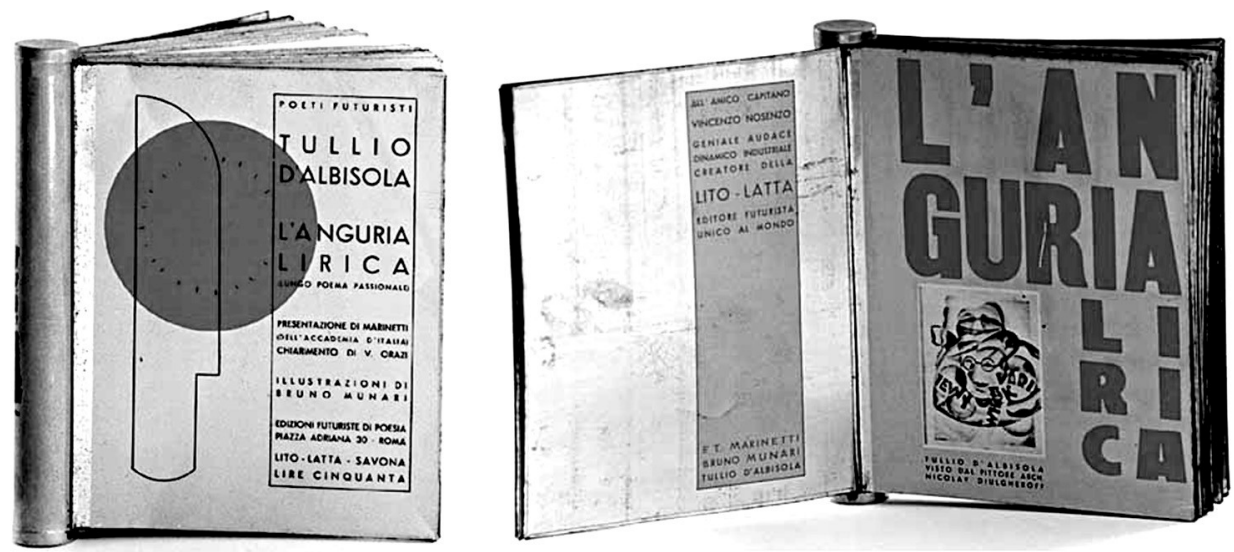

Fig.4: Tullio d'Albisola (1899-1971), L'anguria lírica, 1934.

Fonte da imagem: http://www.tulliodalbisola.it

livros de metal, Marinetti propunha, através do livro, promover uma interação física entre palavras e sensações olfativas, térmicas e táteis. E foi o fundador da Litolatta, Tullio d'Albisola, o autor do segundo e último (ao que se sabe) livro impresso em folhas de metal: L'anguria lírica (Fig. 4), lançado em 1934. A leitura, nesses livros mecânicos, passa a ser também perceptiva - a materialidade de peças de metal atua como significante.

Embora tenha sido moldado pelo Futurismo, o Cubo-futurismo ${ }^{8}$ teve um caráter mais vernáculo. A Rússia possuía uma grande tradição visual - através dos lubki (singular, lubok), toscos cartazetes xilografados contendo textos e ilustrações, e de revistas políticas ilustradas. O futurismo na Rússia aliou-se ao chamado Neoprimitivismo, que explorava a tradição dos lubki e a do folclore, inspirando-se, também, na arte infantil. Uma afirmação de El Lissitsky parece ter se convertido numa espécie de palavra de ordem do Cubo-futurismo: segundo ele, o livro deveria possuir uma eficácia de obra de arte. ${ }^{9}$ Nesse contexto, durante as décadas de 1910 e 1920, artistas plásticos e poetas passam a trabalhar em conjunto na produção de livros, buscando subverter ou renovar sua estética.

${ }^{8} \mathrm{O}$ Cubo-futurismo também se interessava pela pintura cubista.

${ }^{9}$ Ver SILVEIRA. A página violada, p. 194. 
Nascem grupos de artistas plásticos e poetas, como o Grupo $41^{\circ}$ (41 graus), da cidade de Tbilisi (à época, Tiflis). $\mathrm{O} 41^{\circ}$ praticava uma linguagem adjetivada de transracional: a linguagem zaum, baseada na exploração de palavras, fragmentos de palavras, letras e símbolos, incorporando a tipografia, o texto manuscrito, a colagem (incluindo papéis rasgados), a litografia e carimbos, bem como tamanhos de páginas diferenciados (num mesmo volume).

Um sentimento artesanal predomina na produção dos livros cubo-futuristas. Em Ovo de páscoa do futurista Sergei Podgaevskii (Fig. 5), lançado em 1914, Sergei Podgaevskii mescla aquarela, colagem, impressão, papéis rasgados e carimbos. E a impressão por carimbos não se limitou aos tradicionais, emborrachados; Podgaevskii também usou carimbos feitos com batatas cortadas (cujas impressões, nas páginas do livro, remetem a embalagens de ovos de Páscoa). No mesmo ano, Vasily Kamensky e Andrei Kravtsov utilizam papel de parede para compor as páginas de $\mathrm{Nu}$ entre os vestidos (Fig. 6). O livro também apresenta um
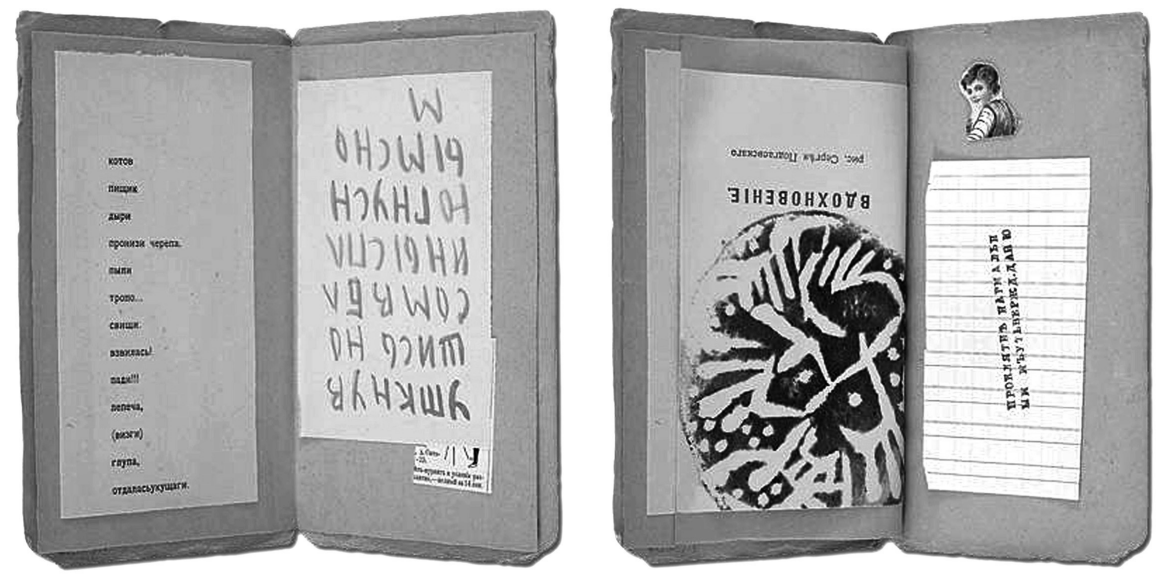

Fig 5: Sergei Podgaevskii, Ovo de páscoa do futurista Sergei Podgaevskii, 1914. Aquarela, colagem, impressão, papéis rasgados e carimbos, 19 x 11,2 cm. Fonte da imagem: http://www.moma.org
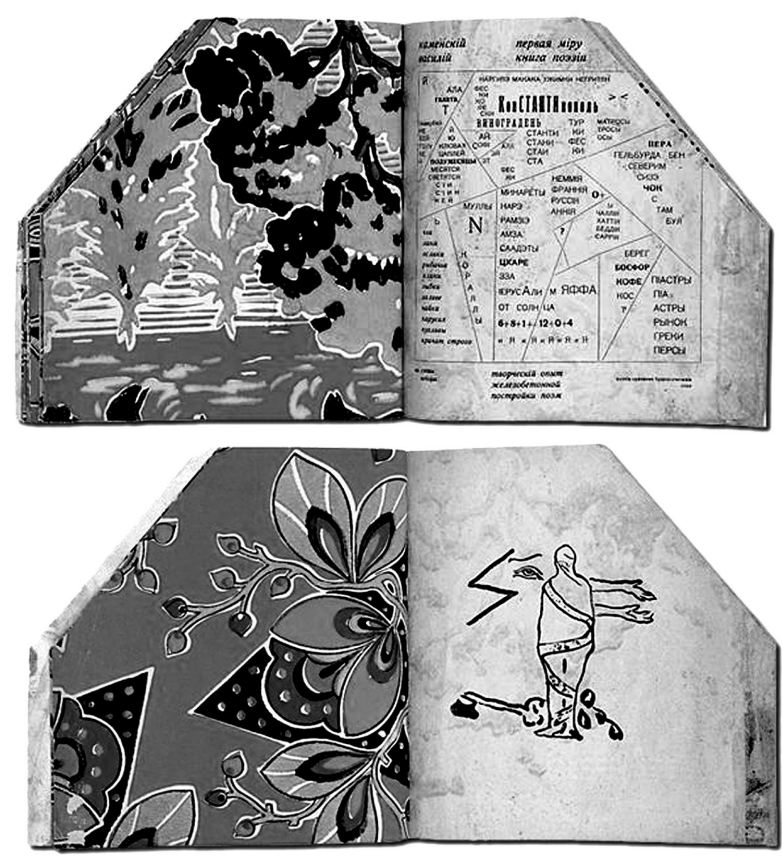

Fig 6: Vasily Kamensky (1884-1961) e Andrei Kravtsov, Nu entre os vestidos, 1914.

Impressões sobre papel de parede, 19,5 x 18,7 cm. Tiragem: 300 exemplares. Fonte da imagem: http://www.moma.org. 
formato inusitado - pentagonal - e combina texto (privilegiando a aspecto visual deste) e imagem, promovendo um diálogo entre poesia e artes plásticas. ${ }^{10}$

Já El Lissitsky privilegiou a funcionalidade. Arquiteto de formação, ele exerceu grande influência no desenvolvimento do design gráfico moderno. Pioneiro na utilização da fotomontagem, os trabalhos mais importantes desse artista típico do Construtivismo russo foram na área do design de livros. Em Para a voz (Fig. 7), livro contendo poemas de Vladimir Mayakovsky, publicado em 1923, El Lissitsky adota uma criativa solução para que os poemas fossem rapidamente localizados. Como numa agenda telefônica, a página inicial de cada poema é acessada por um ícone. O livro inclui trinta poemas de teor revolucionário, que dialogam com formas geométricas e algumas figurativas, que El Lissitsky compôs utilizando, predominantemente, fios tipográficos, peças de metal ou de madeira usadas nas gráficas para imprimir linhas de espessuras variadas. ${ }^{11}$

Para a voz articula a poesia com a política e com a tendência geométrica/construtiva da arte russa de vanguarda, derivada do Cubo-futurismo (o Construtivismo e o Suprematismo). El Lissitsky referenda a premissa de que um livro é, em essência, um objeto manuseável, fazendo jus à designação "construtor do livro", impressa na página de rosto da obra. ${ }^{12}$
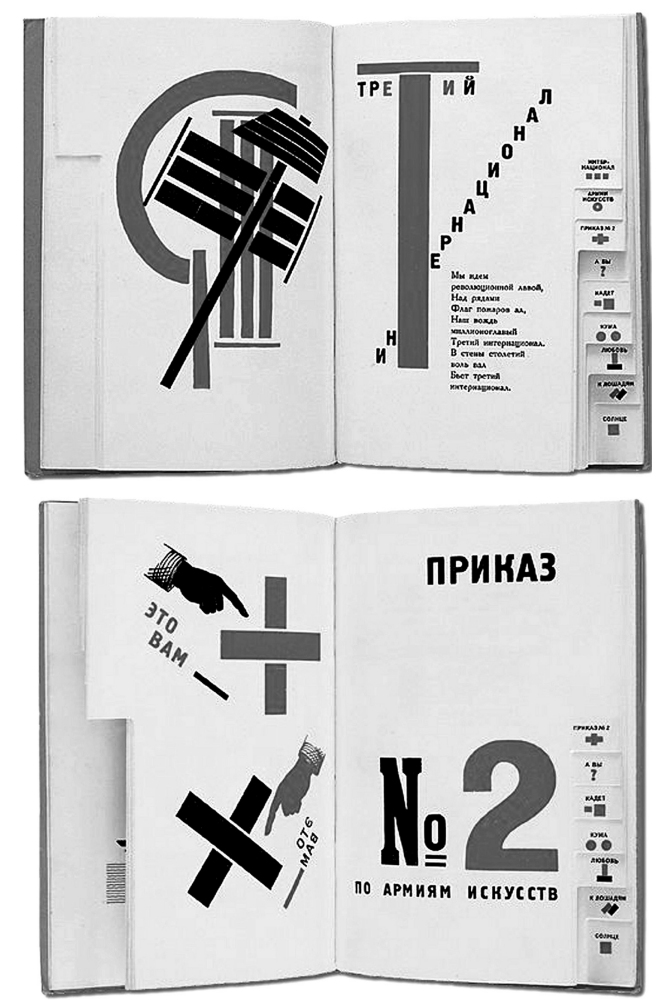

Fig. 7: El Lissitsky (1890-1941) e Vladimir Mayakovsky (1893-1930), Para a voz, 1923. 18,7 x 12,5 cm. Tiragem: 2000/3000.

Fonte da imagem: http://www.moma.org.

\footnotetext{
${ }^{10}$ Vasily Kamensky, em parceria com David Burliuk e Vladimir Burliuk, lançou outro livro confeccionado utilizando papel de parede, Tango com vacas, também em 1914.

${ }^{11}$ HOLLIS. Design gráfico, p. 46.

${ }^{12}$ Conforme edição fac-similar bilíngüe russo-inglês (Cambridge: MIT Press, 2000). Reimpressão em russo a partir de uma edição original de 1923 da The British Library. Versão e adaptação gráfica para o inglês por Peter France e Marta Scotford.
} 
A tendência construtivista da arte européia chega, efetivamente, ao Brasil através da I Bienal de São Paulo (1951). ${ }^{13}$ Derivado da racionalidade construtivista, o Concretismo brasileiro aos poucos se consolida no país. Num contexto de renovação plena das Artes, poetas se aproximam de outras linguagens, como as artes plásticas e a música. E o termo "poesia concreta" surge de forma natural. Em Teoria da poesia concreta, lê-se: "Em sincronização com a terminologia adotada pelas artes visuais e, até certo ponto, pela música de Vanguarda (concretismo, música concreta) diria eu que há uma poesia concreta." 14

A linhagem concretista abordou a estética e a funcionalidade do livro sob óticas distintas. Alguns poetas, como os concretistas mais ortodoxos, encabeçados pelos componentes do grupo Noigandres (Haroldo e Augusto de Campos e Décio Pignatari), cediam espaço a outros meios, que não o livro (o cartaz, por exemplo), para a veiculação dos poemas. Entretanto, o livro foi o primeiro meio usado para veicular um poema típico da fase inicial da poesia concreta: Life (Fig. 8), de Décio Pignatari. $\mathrm{Na}$ fase inicial, ortodoxa, da poesia concreta brasileira, havia uma extrema racionalização da forma e da estrutura. Tal era a ortodoxia, que o movimento preconizava a exclusividade de uma família tipográfica: a futura. ${ }^{15} \mathrm{O}$ design enxuto, ortogonal dos caracteres tipo futura maiúsculos que compõem a palavra life, serviu de base para a estrutura dialética criada por Pignatari. ${ }^{16}$ Concebido

Fig. 8: Décio Pignatari (n. 1927), Life, 1958. Fonte da imagem: BARROS; BANDEIRA. Grupo Noigandres.

\footnotetext{
${ }^{13}$ Essa tendência começa a se instalar no Brasil no fim dos anos 40, mas foi a partir da I Bienal que ela se difundiu, tendo sido apresentada oficialmente aos artistas de modo geral e ao público.

${ }^{14}$ CAMPOS. Poesia Concreta, p. 55.

${ }^{15}$ Posteriormente, incorpora-se mais plenamente a visualidade tipográfica, escapando-se da exclusividade desse tipo.

${ }^{16}$ Estrutura semelhante ao logotipo da revista americana LIFE, uma das fontes de inspiração de Pignatari.
}
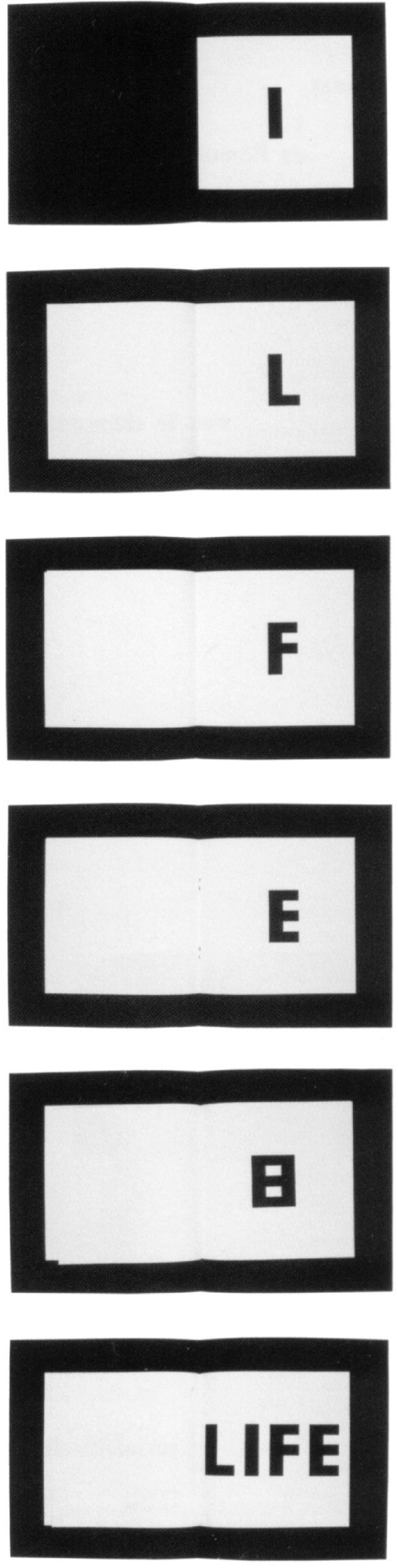
graficamente por Maurício Nogueira Lima, ${ }^{17}$ o poema foi publicado pela primeira vez em 1958, em forma de livreto, no quarto número da revista Noigandres. Life teve diversas versões - em 1962, foi publicado, ainda explorando o formato livro, na Antologia Noigandres 5 , com uma pequena alteração gráfica. ${ }^{18}$

A versão mais difundida de Life foi a de página única; mas houve versões em cartaz, em vídeo, em diapositivos, em computação gráfica - o próprio Pignatari desconhece quantas foram. ${ }^{19}$ Nas versões seqüenciais, diferentemente das versões em página única, as formas retangulares só se tornam reconhecíveis como letras à medida que o leitor folheia as páginas. Esse mesmo ato de virar as páginas é que revela que o poema é um jogo dialético com as letras que compõem a palavra life e o ideograma chinês correspondente a sol. Mas, seja qual for a versão, a estrutura do poema permanece inalterada. A possibilidade de criação de variadas versões de Life deve-se ao fato de a poesia concreta comunicar a própria estrutura do poema. A poesia concreta se subordinava ao veículo, daí a tendência de se cogitar e a possibilidade de se usar outras mídias para a veiculação dos poemas, além do livro.

Se, por um lado, o livro foi questionado dentro do movimento concretista, por outro, foi exaltado. Posicionando-se no pólo oposto a esse questionamento, o poeta Wlademir Dias Pino adota o objeto livro, não como mídia ou veículo, mas como corpo. Participante do Concretismo, Pino divergiu das posições mais radicais do movimento, do qual se desligou para fundar um novo movimento, o Poema-processo. Enquanto a poesia concreta ansiava comunicar a própria estrutura do poema, o Poema-processo converte o poema numa entidade relacional, privilegiando a participação criativa do leitor. Adota-se uma distinção fundamental: a poesia pertence ao universo da língua; o poema, ao universo da linguagem. Desse modo, a palavra torna-se desnecessária (ao conceito de poema), a leitura semântica dá lugar à leitura do processo, à leitura dos estados do poema. Convertido num objeto físico, o poema permanece em estado de projeto, a partir do qual o leitor desenvolve a própria versão. Segundo Pino, no poema-processo, como numa pintura abstrata, não há princípio, nem fim. E foi a condição de objeto manuseável e relacional do livro que permitiu o desenvolvimento da complexa teoria do Poema-processo: ela nasceu a partir de dois livros-poema, criados pelo próprio Pino: A ave e Solida.

Solida (1956-62) é um livro cujas páginas, soltas e contidas numa caixa (Fig. 9), podem desdobrar-se no espaço, tornando-se tridimensionais. As letras que compõem a palavra solida se desagregam e propiciam a criação de outros vocábulos, interagindo com a geometria das formas bi e tridimensionais. De modo semelhante à "explosão tipográfica" nos livros futuristas, nos quais os caracteres se espalham aleatoriamente pela página, as páginas de Solida são programadas para "explodirem" no espaço - mas uma explosão matematicamente calculada - espécie de "explosão geométrica". O estopim:

\footnotetext{
${ }^{17}$ Segundo o próprio Pignatari, em depoimento via e-mail.

${ }^{18} \mathrm{Na}$ sexta e última página,as letras L e E sangram a página. No campo da produção gráfica, sangria é a área de impressão que se estende (sangra) além da margem de corte do papel. Em outras palavras, o corte da página é feito numa área impressa, não há margem branca entre a impressão e o limite da página.

${ }^{19}$ Segundo o próprio Pignatari, em depoimento via e-mail.
} 
o leitor. E a subjetividade de cada leitor faz com que uma explosão nunca seja igual à outra. Às vezes, a poética do livro de artista dialoga com o conceito de escultura: é o caso de Solida.

O primeiro livro de artista brasileiro foi A ave (Fig. 10), elaborado a partir de 1954 e lançado em 1956. As páginas de A ave variam em formato, cor e textura. Mesclando trabalho artesanal e reprodução mecânica, A ave é composto por páginas brancas,

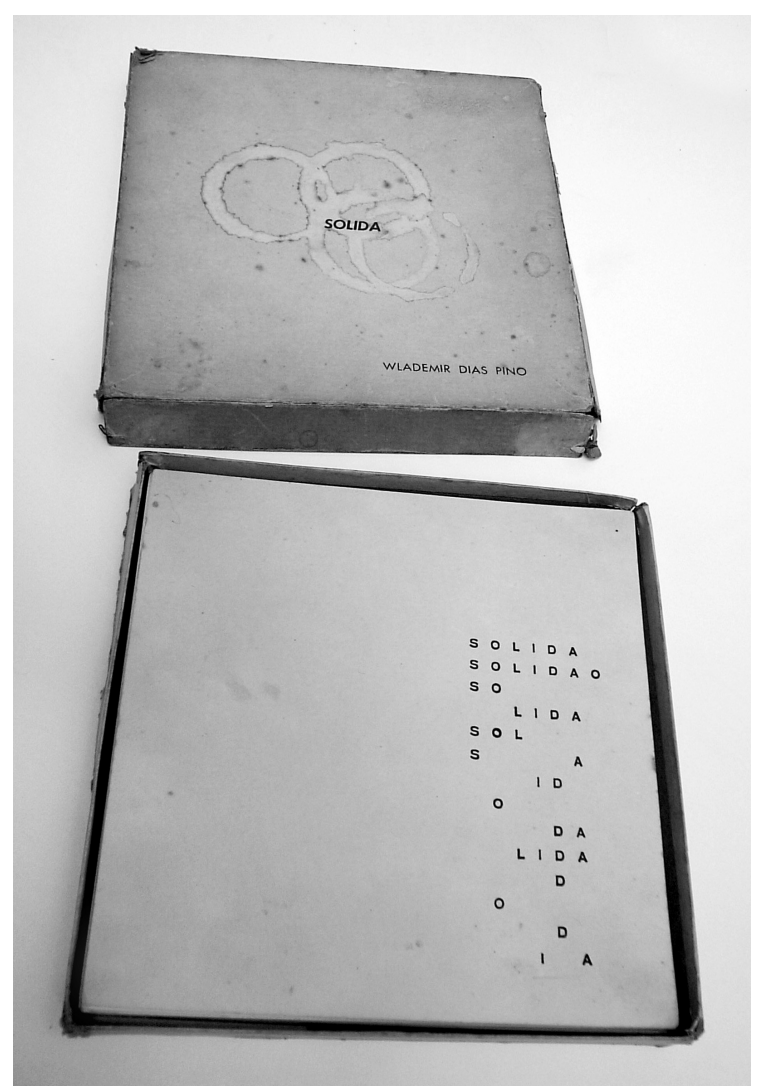

Fig. 9: Wlademir Dias Pino (n. 1927), Solida, 1956-62. Foto: Angelo Mazzuchelli
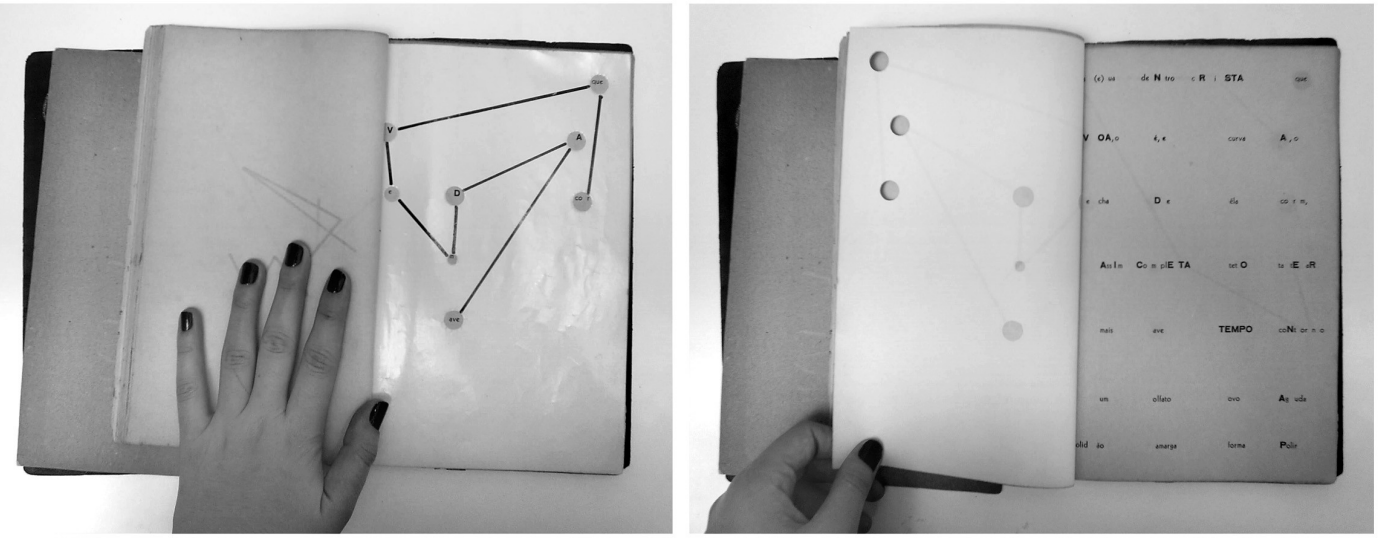

Fig. 10: Wlademir Dias Pino, A ave, 1956. Foto: Angelo Mazzuchelli. 
coloridas, opacas, semitransparentes, foscas e brilhantes. As páginas semitransparentes permitem a visão parcial da página seguinte. Alguns furos circulares em outras páginas cumprem a mesma função das semitransparentes. $O$ texto possui variações tipográficas:

\section{A AVE VOA DEnTRO de sua COR;}

polir O VOo Mais que A UM ovo;

que taTEar é SEU ContORno?

SUA agUda cRistA compLeTA a solidão;

assim é que ela é teto DE SEU olfato;

\section{a curva amarGa SEU Voo e fecha Um TempO com Sua fOrma.}

Essa alternância entre minúsculas e maiúsculas, juntamente com a semitransparência e os furos, permite que alguns caracteres surjam num outro contexto formando outra(s) palavra(s). Essas novas palavras são formadas com o auxílio dos gráficos, desenhos geométricos feitos a nanquim, que indicam direções de leitura. A exploração simultânea desses artifícios proporciona uma interpenetração de páginas, verticalizando o texto: a leitura torna-se tridimensional, e vincula-se à manipulação do livro. A encadernação permite até mesmo que as páginas possam ser soltas. Segundo Pino, A ave é um livro que se explica ao longo do uso: "é a expressão do próprio material usado no livro: a paginação, a página em branco, as permutações de folhas, o ato de virar as páginas, a transparência do papel, o corte, os cantos etc." ${ }^{20}$

Em $A$ ave, o vínculo estabelecido entre os signos verbais, os diferentes artifícios (gráficos, furos, cores e formatos de páginas) e a manipulação do livro sugerem uma leitura que poderia ser classificada como caleidoscópica - uma leitura que joga com o já visto e o que está por vir - para a qual todos os elementos gráficos e plásticos concorrem efetivamente. Toda a magia de um caleidoscópio está no giro, na manipulação desse instrumento ótico. As diferentes imagens formadas a cada giro do caleidoscópio são combinações dos mesmos minúsculos objetos coloridos nele contidos. Um giro de um caleidoscópio poderia corresponder a uma virada de página de $A$ ave, devido às remições e projeções gráficas que a leitura do livro proporciona. Evidentemente, existe um texto verbal em $A$ ave; mas a ênfase plástica/material dada às páginas faz com que a carga semântica dos caracteres quase que se dilua ao longo do livro. Os signos verbais escritos, que "nada mais são do que uma combinação de algumas retas e de algumas curvas", ${ }^{21}$ incorporam com maior plenitude a dimensão gráfica nesse livro-poema. Folhear as páginas coloridas, furadas, cortadas, de A ave referenda que os signos gráficos também são forma; que os signos gráficos também são cor; e que podem ainda ser brilho, opacidade, textura: a leitura do livro é ditada por esses aspectos.

\footnotetext{
${ }^{20}$ PINO. Processo, s.p.

${ }^{21}$ BARTHES. O óbvio e o obtuso, p. 93.
} 
Os livros-poema de Pino espelham e extrapolam a concepção de livro nascida com o Modernismo. Os livros cubo-futuristas exploravam as qualidades plásticas dos materiais utilizados; a lógica de $A$ ave, por exemplo, não se baseia nas qualidades, mas nas propriedades dos materiais (como a transparência das páginas). Tal como Un coup de dés, A ave e Solida solicitam uma leitura global e o dinamismo do jogo de movimentos, dos quais nos fala Blanchot. Mas nos livros-poema, essa leitura e esse dinamismo são mais efetivos, devido às qualidades plásticas dos mesmos. A exploração das propriedades dos materiais utilizados nos livros-poema faz com que livro e poema se confundam, convertendo-se em entidades indistintas e inseparáveis: ambos os poemas existem porque existem os livros, que são corpos, não veículos. Esse vínculo inviabiliza a transposição desses poemas para outras mídias, diferentemente de Life, que pôde ser transposto para diferentes mídias, sem que houvesse comprometimento da estrutura do poema. Já o conceito de simultaneidade de La Prose du Transsibérien et de la petite Jehanne de France nasce da justaposição dialética de texto e imagem (pintura). Nos livros-poema de Pino, a simultaneidade também está ligada à subjetividade e à manipulação dos livros.

Tal como pretendiam os Futuristas italianos com os livros de metal, Pino também cria livros-signo: livros signos do próprio livro. "Corpo(s) movendo-se em espaço e tempo", ${ }^{22}$ os livros-poema possuem aquela eficácia de obra de arte, como desejara o russo El Lissitsky, o "construtor de livros" - título ao qual Pino também faz jus.

\section{A B S TRACT}

This essay deals with the link of the visual poetics of literature to the concept of the poem as an art object to be handled. It focuses on some of the early European modernist works that can be categorized as as "book-objects" or artist's books. It then turns to Brazilian Concretism, from which the poet Wlademir Dias Pino departed to create the "Poema-Processo" movement, whose theories emerged from his creation of two books: A Ave - considered the first Brazilian artist's book and Solida.

\section{KEYWORDS}

Artist's-book, book-object, book-poem

\footnotetext{
${ }^{22}$ O livro ideal, segundo El Lissitsky. Ver SILVEIRA. A página violada, p. 194.
} 


\section{REFERÊNCIAS}

BARROS, Lenora; BANDEIRA, João (Org.). Grupo Noigandres: arte concreta paulista. São Paulo: Cosac \& Naify; USP, 2002.

BARTHES, Roland. O óbvio e o obtuso. Trad. Léa Porto de Abreu Novaes. Rio de Janeiro: Nova Fronteira, 1990.

CAMPOS, Augusto de. Poesia concreta. (1955). In: CAMPOS, Augusto de; PIGNATARI, Décio; CAMPOS, Haroldo de. Teoria da poesia concreta: textos críticos e manifestos 1950-1960. (1965). 4⿳a ed. São Paulo: Ateliê Editorial, 2006, p. 55-57.

HOLLIS, Richard. Design gráfico: uma história concisa. Trad. Carlos Daudt. São Paulo: Martins Fontes, 2001.

JEAN, Georges. A escrita: memória dos homens. Trad. Lídia da Motta Amaral. Rio de Janeiro: Objetiva, 2002.

LISSITSKY, El; MAYAKOVSKY, Vladimir. For the Voice. (1923). Edição fac-similar bilíngüe russo-inglês: Adaptação para o inglês do original em russo: Peter France e Marta Scotford. Cambridge, MA: MIT Press, 2000.

PEYRÉ, Yves. Peinture et poésie: le dialogue par le livre. Paris: Gallimard, 2001.

PIGNATARI, Décio. Depoimento. e-mail para o autor, maio de 2004.

PINO, Wlademir Dias. Processo: linguagem e comunicação. Petrópolis: Vozes, 1973.

SCUDIERO, Maurizio. The Italian Futurist Book. Disponível em <http://colophon.com/ gallery/futurism/index.html> Data de acesso: ago. 2005.

SILVEIRA, Paulo. A página violada; da ternura à injúria na construção do livro de artista. Porto Alegre: UFRS, 2001.

TULLIO D’ALBISOLA. Disponível em < http://www.tulliodalbisola.it > Data de acesso: out. 2005. 